\title{
Patent policy regulation and public health
}

\author{
Anna Rita Bennato ${ }^{1}$ Monica Giulietti ${ }^{1}$
}

Received: 28 January 2019 / Revised: 3 June 2019 / Accepted: 3 August 2019 /

Published online: 12 August 2019

(c) The Author(s) 2019

\begin{abstract}
This paper analyzes the impact of the trade-related aspects of intellectual property rights (TRIPS) agreement on social welfare, when the effects on public health are taken into account. In particular, we study how the new international patent policy affects social welfare through the availability of pharmaceutical products. Extending the model developed by Grossman and Lai (Am Econ Rev 94(5):1635-1653, 2004) on optimal patent protection, this paper examines the externality generated by the intellectual property rights enforcement on our definition of public health.
\end{abstract}

Keywords Intellectual property rights $\cdot$ Patent law $\cdot$ Health

JEL Classification F13 $\cdot \mathrm{I} 10 \cdot \mathrm{O} 34$

\section{Introduction}

International policies to protect intellectual property rights (IPRs) have seen important changes during the past two decades. Rules on patents, copyrights, trademarks, and other forms of IPRs have become a standard component of international trade agreements. In 1994 during the Uruguay Round, developed countries made the upgrading of IPRs protection one of their highest priorities, setting up the agreement on trade-related aspects of intellectual property rights (TRIPs). The TRIPs agreement calls on countries to enforce a minimum standard of protection lasting 20 years for several categories of intellectual property, ensuring the same treatment in all subject matters without considering the peculiarities of each good, including pharmaceuticals.

Historically, the issue of intellectual property rights is considered a contentious one. The primary reason for providing patent protection is to permit inventors to earn returns on their inventions, and therefore to provide an incentive for technology to advance. In the absence of some form of protection, private agents will have weak

Anna Rita Bennato

A.Bennato@lboro.ac.uk

1 School of Business and Economics, Loughborough University, Loughborough, UK 
reasons to invest their resources in generating new information and technologies. On the other hand, though spurring the production of a greater variety of goods, this institution enhances the firms monopolistic power and so it leads to an inefficiently low level of output.

A fundamental tension exists between the social desirability of widespread dissemination of available knowledge and the need for society to provide adequate rewards to suppliers of new inventions (e.g. see Chin and Grossman 1990; Deardorff 1992). On top of that, another important aspect of this issue lies in the possible adverse welfare effects that would be caused by extending intellectual patent protection indiscriminately to all goods across the world. Beyond the common wisdom according to which IPRs are an important factor to foster economic growth, an opposite view is argued equally vehemently (Mansfield 1985; Diwan and Rodrik 1991; Deardorff 1992; Maskus and Penubarti 1995). The main point of contention is the claim made by governments of many poor developing economies that unqualified patent protection for pharmaceuticals will result in substantially higher prices for medicines, with adverse consequences for the health and well-being of their citizens, and not only. Hence, welfare implications that derive from a strict enforcement of IPRs are complex. The simple fact that trade flows rise or fall in response to an enforcement of the law on IPRs is not sufficient to draw conclusions regarding economic welfare. Both static and dynamic effects need to be considered (Deardorff 1992; Helpman 1993).

The aim of this paper is to study how the new international patent system affects social welfare by changing the availability of pharmaceutical products. ${ }^{1}$ The extension of patent protection to pharmaceuticals yields an externality in terms of deterioration of health, both in developed and developing countries. In actual facts, the high integration of travel and transport has caused an acceleration in the transnational spread of viruses, and the control of infectious diseases has become more difficult. ${ }^{2}$ In other words, communicable diseases which traditionally are linked to poverty, could become common also in the developed world. The recent facts about the diffusion of communicable diseases, due for example to social contagion across social networks (see Schwamm 2018), have showed us how developed countries are vulnerable to "neglected diseases". Policies dealing with infective diseases are of great importance nowadays. Yet, only recently economists have begun to look at these questions in a formal way (Gersovitz and Hammer 2004). In the light of the above observations, our aim in the current paper is to rethink the role of patent protection in the pharmaceutical sector, studying the welfare implications according to different levels of public health.

With this purpose we extend the set-up developed by Grossman and Lai (2004) by including explicitly the health sector. The main assumption is that agents derive

\footnotetext{
1 Intellectual property rights include a large range of legal tools apt to protect inventions; literary and artistic works; and symbols, names and images used in commerce (i.e. copyrights, industrial design, patents, trademarks, etc.) In the current work we focus our analysis on the optimal patent policy, and we will use IPR(s) exclusively to refer to patent(s).

2 About the global dimension of non-communicable diseases see Murray and Lopez (1996).
} 
utility from individual consumption of pharmaceutical goods, while at the same time their utility is increasing in the level of the national health. Individual utility depends on the individual health, and this in turn is influenced by personal consumption of drugs and benefits positively from the presence of a healthy environment. At the same time, it is by increasing their personal utility level that individuals contribute to an enhancement of the social health. Focusing on one of the legal tool adopted to protect IPR, we investigate how it is possible to define the optimal patent system in a world where individuals consume "good health" in the terminology of Grossman $(1972,2000)$. In the current paper, we define health differently from the classical approach. ${ }^{3}$ According to the Grossman's seminal work (1972), we assume that health is a good desired to enhance well-being and so utility, and vice versa through individual utility the health increases. Consumer's utility is affected by individual pharmaceutical purchases, which in turn contribute to an improvement of the social welfare. In other words, a sort of positive externality is at work. Being in good health not only contributes to the wellbeing of a single individual, but it benefits also people that are surrounded by healthy subjects, from family members to colleagues at work. If everybody takes care of her own health, each individual contributes directly to an improvement of the social health, creating positive effects which are beneficial to everyone. On the contrary, being in poor health conditions triggers a set of costs which can be directly matched to the single individual affected by the problem (e.g. inability to go to work), and indirectly link to the affected subject (e.g. crowded hospitals/GPs). For example, in the very recent times we are witness of the diffusion of new waves of pandemic diseases which are causing important social costs. $^{4}$

In the current analysis we assume that individuals do not internalize this social externality when maximizing their utility. In other words, consumers ignore the existence of a positive externality which reduces the risks of diffusion of infectious diseases. ${ }^{5}$ Since the patent policy affects the monopolistic prices, the choice of the optimal patent life must weigh its relation with possible externalities. In order to determine the optimal patent policy, we have to balance two opposite effects that influence the level of social welfare, re-examining the trade-off between static costs and dynamic benefits that was first studied by Nordhaus (1969). ${ }^{6}$ First of all, we

\footnotetext{
3 Throughout the classical literature, health is described as a durable capital stock that produces an output of healthy time. According to the classical approach health represents both a form of human capital (Mushkin 1962; Becker 1964; Fuchs 1966; Cropper 1977; Clerico 1984; Howitt 2004), and a productive asset. In this last case healthier workers are physically and mentally more energetic and robust, so they are less likely to miss work due to illness, either of themselves or their families.

4 Vaccination campaigns have been always considered one of the most important public policies to protect and improve health. Lately, lack of trust towards this important form of intervention has exposed entire populations in the developed world to new waves of diseases which were considered as having been eradicated, e.g. see the case of the measles outbreak in New York State: https://www.nytim es.com/2019/04/29/health/measles-outbreak-cdc.html?module=inline.

5 Since they are not considering this externality, consumers are available to pay for each medicine a lower price than the optimal one.

${ }^{6}$ In our analysis governments choose an optimal patent policy by endogenizing the health externality. Alternatively, by relying on a system of subsidies which aims to promote the consumption of more medicines, governments could fix the health externality problem directly. To this end a change in the taxation
} 
know that patent protection yields a positive effect, because a longer-lasting patent life increases the number of inventions (Nordhaus 1969; Grossman and Helpman 1991). More precisely, this benefit is present if we can identify an equilibrium where a larger supply of inputs are combined to produce a larger amount of patented goods. On the other hand, we cannot disregard the detrimental effects in terms of welfare from a static point of view. A longer patent length implies a longer monopolistic power, with all the ensuing inefficiencies associated with monopoly.

In a closed economy, where the extent of the health externality is connected with the consumption level of pharmaceutical goods, the identification of the optimal patent protection is crucial for the social welfare, and the optimal patent length turns out to be increasing in the health externality. ${ }^{7}$ The approach adopted in this paper is based on the concept of international surveillance of communicable diseases as a global public good, necessary to preserve global health (Kaul et al. 1999).

This paper is organized as follows. In the next section we develop our first analysis of a simple model with ongoing innovation. In Sect. 3 we study the optimal patent policy in a closed economy. Through a numerical simulation, we measure the welfare effects in a country that has no trade with the rest of the world, focusing on the health sector. In Sect. 4 we consider a world economy in which there are two countries that differ with respect to both the market size, along with the capability of conducting research and development, and their health externality. Finally, we develop our conclusions in Sect. 5.

\section{The basic model}

We consider a small closed economy with ongoing innovation protected by IPRs where there are two types of agents: consumers and firms. This model generates a precise formula that characterizes the trade-off between static costs and dynamic benefits of strengthening the patent protection. Our economy has two sectors: sector one which produces a homogeneous good under perfect competition, and sector two which produces a continuum of differentiated products, namely pharmaceutical drugs under monopolistic competition. Following Grossman and Lai (2004) (henceforth G\&L) we assume that the realization of differentiated products is the result of private investments in $\mathrm{R} \& \mathrm{D}$. To guarantee adequate returns from investments in research, in this economy the innovator-producer enjoys the exclusive right to produce and supply its own IPR-protected good. It follows that the welfare cost

\footnotetext{
Footnote 6 (continued)

system would be needed. Given the social costs generated by a taxation system (i.e. consumers price, market competition, pass-through, etc.), we remain agnostic on this regard, and instead we focus on the protection of intellectual property right policies promoted by governments.

7 Assuming a full enforcement of the patent protection laws, we believe in the benefit that derives from an international agreement that protects the patent right. But, we consider that the life of each patent must be analyzed according to the peculiarities of each good. We deem that the utility deriving from a good such as a packed orange drink is different from the utility coming from another kind of good, such as the malaria vaccine.
} 
of providing patent protection stems from the fact that the patent-holder is allowed to exercise its full market power for the new product, letting the monopolist prevent other agents from accessing the new products (deadweight loss). However, to achieve a desirable balance between incentives to inventors and benefits for consumers, patent protection is granted for only a limited period of time. In our model, we assume that the patent length cannot be larger than the normal time for a products to became obsolete, that is the finite economic life length of an invented good defined by $\bar{\tau}{ }^{8}$ It should be noted that $\bar{\tau}$ also represents the period of time during which consumers gain utility from the patented good, before it will become obsolete.

\subsection{Demand side}

In our economy, preferences of a representative consumer are characterized by

$$
U(c, v)=c+v(H, \bar{H}),
$$

where $c$ is the utility coming from the consumption of the homogeneous good, and $v$ is the utility a consumer enjoys from both the individual and social health level, $H$ and $\bar{H}$ respectively. The subutility $v$ has the following Cobb-Douglas form:

$$
v(H, \bar{H})=H^{\alpha} \bar{H}^{1-\alpha},
$$

with $0<\alpha<1 .^{9}$ In our specific framework, $H$ represents the utility deriving from the consumption of drugs, whereas $\bar{H}$ represents the utility that a representative individual derives from the state of the social health, measured by good health. Equation (2) incorporates an important externality into the health subutility function, whose magnitude is captured by $(1-\alpha)$. More specifically, through the consumption of pharmaceutical drugs an individuals satisfy not only their own needs, but they exert a relevant influence on the level of public health. This externality identifies the benefits that the representative consumer receives from living in a healthy environment. Hence, we define $H$ as the sum of the subutilities gained from the consumption of each pharmaceutical drug. Precisely, $H$ is the total utility obtained by consuming a bundle of pharmaceutical products available in the economy, defined as:

$$
H=\int_{0}^{n(t)} h[x(i, t)] d i,
$$

where $h$ is the generic utility function for each different drugs, $x(i, t)$ represents the consumption of the $i$ th variety of differentiated pharmaceutical product at time $t$, $n(t)$ is the number of differentiated pharmaceutical products invented before $t$ which still have a value for consumers at time $t$. By assumption $h(x)$ is increasing and strictly concave, i.e. $h^{\prime}(x)>0$ and $h^{\prime \prime}(x)<0$, and to ensure a positive demand for

\footnotetext{
${ }^{8}$ According to the TRIPs agreement, currently a patent lasts for 20 years. During the Uruguay Round it has been claimed to be the lapse of time before a new good is defined obsolete.

9 Note that $\frac{\partial v}{\partial H}=\alpha H^{\alpha-1} \bar{H}^{1-\alpha}$. However, since ex post $H=\bar{H}$, it follows that $\frac{\partial v}{\partial H}=\alpha$..
} 
each variety at any finite price, we assume $h^{\prime}(0)=\infty .{ }^{10}$ Although the decision to purchase a pharmaceutical good may involve different categories of people, and the decision-making process varies from country to country, to simplify the analysis in the current paper we omit these aspects. ${ }^{11}$ More precisely, we adopt the standard economic theory assuming that the decision to purchase a good (including pharmaceuticals), to make the payment, and then to consume it is undertaken individually by the single person. Moreover, following G\&L, in the current analysis we make the simplifying assumption that the demand for differentiated products does not vary with respect to income. Thus, a rich country does not have a larger market for such a type of goods than a poor country. Individuals love spending money to buy different medicines because via their consumption they can increase their own health's level. The consumer budget constraint is defined as

$$
w(t)=c+\int_{0}^{n(t)} p(i, t) x(i, t) d i .
$$

where $c$ is the consumed quantity of the homogeneous good, whose price is set equal to 1 since we treat it as the numéraire, and $p(i, t)$ is the price of a single drug at time $t .^{12}$ The consumer's objective is to maximize her utility by purchasing all varieties that are not yet obsolete. ${ }^{13}$ Hence, her maximization problem is defined by the objective function (1) subject to constraint (4), given (2) and (3). We assume that the representative consumer behaves as follows: initially, she chooses a bundle of goods according to her first-order condition

$$
\alpha h^{\prime}[x(i, t)]=p(i, t) \quad \forall i=0 . . \infty \text { and } \forall t=0 . . \infty,
$$

after which, she devotes her remaining expenditure to buy the homogeneous good. Clearly, from the equilibrium condition in (5) it emerges that the consumer demand of pharmaceutical products is increasing in $\alpha$.

\subsection{Production side}

We assume that in sector one firms determine the level of production of the homogeneous good by maximizing their profits under certainty. In sector two all firms are innovators and, following Nordhaus (1969), the output produced by a firm is a function of the amount of inventive inputs. More precisely, each firm devotes a

\footnotetext{
${ }_{10}$ Additionally, imposing the condition $\frac{-x h^{\prime \prime}(x)}{h^{\prime}(x)}<1$ for all $x$, we ensure that every firm charges a finite price for its own differentiated product.

${ }^{11}$ For instance, doctors, pharmacists and insurers, having different weights all contribute to the drug choice. For more details about this complex process, see Fink (2000).

${ }^{12}$ If we adopt the common view of treating health as capital (Grossman 1972), in our case we have that the stock of health is subject to a total depreciation every year. It follows that $H_{t+1}-H_{t}=I_{t}-\delta H_{t}$, and where $\delta=1$ and then $H_{t+1}=I_{t}$.

${ }^{13} \mathrm{We}$ are ignoring the fact that individuals could be interested in buying obsolete goods. For example, some therapies, considered obsolete in the developed world, could still represent a vital medical care in some developing countries.
} 
certain quantity of labour in $R \& D$ to increase technological knowledge, along with a constant stock of unskilled workers. Thus, the production of the differentiated good is described by the following CES function

$$
\phi(t)=F\left[L_{H}, L_{R}(t)\right]=\left\{b\left[L_{R}(t) / a\right]^{\beta}+(1-b) L_{H}^{\beta}\right\}^{1 / \beta},
$$

where, following $\mathrm{G} \& \mathrm{~L}, \phi(t)$ represents the flow of new inventions at time $t$, while $L_{H}$ and $L_{R}{ }^{14}$ are the constant unskilled workforce and the variable amount of labour devoted to $\mathrm{R} \& \mathrm{D}$ respectively, and $\beta \leq 1 / 2 .{ }^{15}$ Finally, $a$ measures the production coefficient, which corresponds also to the level of technology employed in the production process. Moreover, $a$ units of labour is the same amount of input needed to produce 1 units of homogeneous good. Perfect competition in the market of the homogenous good leads to the typical equilibrium condition for the wage level, where $w=1 / a$. Perfect labour mobility ensures a unique wage rate. In the competitive market for the homogeneous good, the equilibrium is described by

$$
p_{c}=a w=1 .
$$

We assume that all goods invented at time $t$ become obsolete at time $t+\bar{\tau}$. Then, it follows that the rate of innovation in our economy is given by:

$$
\dot{n}(t)=\phi(t+\bar{\tau})-\phi(t),
$$

which depends on the growth of the number of inventions happened after a specific time lag. Recalling the actual patent extent, the rate of innovation is equal to the difference in the flow of new products after 20 years. ${ }^{16}$

In order to simplify the notation, hereafter we omit the time subscript and we assume that the flow of new invention, $\phi$, does not change over time, and in the stationary equilibrium the rate of innovation is constant. Following the hypothesis that all investments in innovation are sunk so that new knowledge is available at zero marginal cost (Nordhaus 1969), we assume that research programs chosen by innovators are able to yield immediate results. Hence, it follows that every firm uses a new technology for $\bar{\tau}$ years. In our economy innovation is the result of private investments for which the inventor is the exclusive owner of its own advancements (see among others Nordhaus 1969; Grossman and Helpman 1991). As in G\&L, the labour force employed in manufacturing the differentiated goods is just the amount

\footnotetext{
14 Notice that $L_{H}+L_{R}=L$. Following the Schumpeterian-Nordhaus approach, the spending $E$ is always positive in equilibrium, and the aggregate equilibrium is described by the usual equality between investment and saving, $Y-E=S$. Since national income is define as $Y=r L_{H}+w L+n_{m} M \pi$, after some substitutions, we obtain that the aggregate expenditure in equilibrium is $E=w\left(L-L_{R}\right)+n_{m} M \pi$, where $n_{m}$ represents the number of firms which hold a patent.

15 This assumption corresponds to the hypothesis that the elasticity of substitution between the two inputs is $\leq 2$. As it is clearly explained in G\&L, this assumption is sufficient, but not necessary, to ensure that any patent policy that satisfies the FOC for an interior point, satisfies also the SOC.

${ }^{16}$ In line with this assumption, we are assuming that the speed of innovation is given by the amount of labour applied in the R\&D sector. Then, if the flow of new products is $\dot{n}$, the total human capital employed in R\&D is equal to $a \dot{n}$ (see Grossman and Helpman 1991).
} 
needed to satisfy the demand at the equilibrium price. Then, the equilibrium of the firm in sector two is described by

$$
\eta F_{L}\left(L_{H}, L_{R}\right)=w,
$$

where $\eta$ represents the value of the new patent, which corresponds to:

$$
\eta=\frac{\omega M \pi(\alpha)}{\rho}\left(1-e^{-\rho \tau}\right),
$$

where $\pi$ defines the monopolist profit, $M$ describes the number of consumers (size of the market), $\rho$ is the constant discount rate, and $\omega \in[0,1]$ measures the strength of the government policies enforcement. It is important to note that governments who aim to protect the patent holder right introduce a set of policies which define both the time-length of IPR and the breath of its enforcement. Hence, the value of the new patent depends on both $\tau$ and $\omega$, and it is given by the discounted expected flow of profits until the patent expires $(t<t+\bar{\tau})$. From Eqs. (9) and (10) it emerges clearly that a rise in either patent length or patent enforcement increases the value of a new patent. Following the Nordhaus's approach, for which in equilibrium each patent holder firm behaves as a monopolist, we have that in equilibrium all monopolistic firms equate their marginal revenues with their marginal cost

$$
w a=p\left(1-\frac{1}{\epsilon}\right)
$$

where $w$ is the constant wage rate, $(1-1 / \epsilon)$ is the markup and $\epsilon$ corresponds to the demand elasticity. ${ }^{17}$ The consumer equilibrium for the differentiated good is defined by $\alpha h^{\prime}(x)=p_{m}$. This expression helps us to find out how the level of $\alpha$ influences the equilibrium price and the demand for a differentiated good. After a simple differentiation, ${ }^{18}$ we obtain:

$$
\frac{d x}{d \alpha}=-\frac{h^{\prime}(x)}{\alpha h^{\prime \prime}(x)}>0 .
$$

It follows that the greater is $\alpha$ (or the lower is the level of the health externality, $1-\alpha)$, the higher is the demand level for a pharmaceutical good, since individuals always prefer to increase their utility from increasing the consumption of drugs. From the total differentiation of Eq. (5) we can see that, if $\alpha$ does not vary, we have a negative relationship between demand and price for pharmaceuticals

$$
\alpha h^{\prime \prime}(x) d x=d p \rightarrow \frac{d x}{d p}=\frac{1}{\alpha h^{\prime \prime}(x)}<0
$$

\footnotetext{
17 The monopolist profit is defined as $\pi=p x-p\left(1-\frac{1}{\epsilon}\right) x$. Clearly, from the marginal revenues we are able to see that the monopolist will always choose an output level such that the elasticity of demand is $\epsilon>1$..

18 Differentiating $\alpha h \prime(x)=p_{m}$ we get $d p=h^{\prime}(x) d \alpha+\alpha h^{\prime \prime}(x) d x$. Assuming a price constant over time, we can derive the relationship between $\alpha$ and $x$ by a simple manipulation.
} 
Hence, we end up with a demand function that is decreasing both in price and in the externality. Using Eq. (12) we easily obtain the expression for the elasticity of the demand with respect to $\alpha$ as follows

$$
\epsilon_{\alpha}=\frac{d x}{d \alpha} \frac{\alpha}{x}=-\frac{h^{\prime}(x(\alpha))}{h^{\prime \prime}(x(\alpha)) x}>0 .
$$

To sum up, if a country has a low level of externality and is hit by a pandemic, its citizens tend to purchase more pharmaceuticals with a greater impact on prices. Therefore, where the production of pharmaceutical goods is in the hand of monopolistic firms, the price level increases more with an ensuing deterioration of social welfare.

\section{The optimal patent policy in a closed economy}

In this section we study the government's maximization problem. Following G\&L, we refer to the strength of intellectual property rights (IPRs) as a vector of polices $(\tau, \omega)$, which captures both the time-length of the patent and the stringency of its enforcement policies. Governments choose a package of policies, which includes also other instruments, such as limits on patentability, compulsory licensing requirements, copyright and trademark protections, and so on. The parameter $\omega \in[0,1]$ identifies the probability that a non-expired patent is made compulsory by the government, at any moment in time. Alternatively, $\omega$ is also the fraction of the country's territory in which the patent is enforced. The parameter $\tau$ represents the patent duration recognized by the policy maker, within the economy. Obviously, the government assigns to patent holders the exclusive right to produce and sell the protected good in the local market. The present discounted value of a stream of income of one dollar, from time $t=0$ to $\tau$, is given by

$$
T \equiv\left(1-e^{-\rho \tau}\right) / \rho .
$$

From this expression, we see that the optimal level of research is decreasing in $\rho$, the constant discount rate. If the discounted value of the flow of revenues in the interval from $t=0$ to $t=\tau$ rises, the volume of research activities that is profitable to perform improves. Moreover, research efforts increase with the life of the patent. ${ }^{19}$ From above, we define the patent policy in place in our economy as follows

$$
\Omega=\omega T .
$$

Hence, we can rewrite the value of a new patent, previously defined in equation (10), as follows:

$$
\eta=\Omega M \pi(\alpha)
$$

\footnotetext{
${ }^{19}$ More specifically, $d T / d \tau=e^{-\rho \tau} / \rho>0$, whereas the effect of the interest rate is negative, $d T / d \rho=-[\tau \exp (-\rho \tau)-T] / \rho$.
} 
In our analysis we refer to $\Omega$ as the instrument through which we capture the whole set of incentives that the government provides for the realization of new inventions, and at the same time, it also measures the strength of the IPR protection available in our economy. The new optimal patent policy will be set by the policy maker in order to maximize his objective function, which is the social welfare. We solve the government's maximization problem to determine the optimal length of intellectual property rights with the aim to minimize the deadweight loss deriving from the patent system. Before proceeding, it is useful to specify some aspects. As a measure of the social welfare we use the net surplus of the economy, which comprises the consumers surplus and the producers surplus minus resource costs. At any time, the consumer enjoys a surplus of $C_{m}$ from the consumption of goods whose patent is enforced and a surplus of $C_{c}$ from the consumption of differentiated products which are sold at a competitive price, either because the patent has expired or because production is not protected (homogeneous good). Hence, the two levels of surplus are defined as

$$
\begin{gathered}
C_{m}=h\left(x_{m}(\alpha)\right)-p_{m} x_{m}(\alpha), \\
C_{c}=h\left(x_{c}(\alpha)\right)-p_{c} x_{c}(\alpha) .
\end{gathered}
$$

The two quantities $x_{m}$ and $x_{c}$ represent the amount of goods purchased by the representative consumer from a monopolistic and competitive supplier, respectively. Since our aim is to investigate the externality effects that involve both types of consumer surplus, we proceed according to the following steps. First of all, we differentiate the monopolistic consumer surplus defined in Eq. (16) as

$$
\frac{d C_{m}}{d \alpha}=h^{\prime} \frac{d x_{m}}{d \alpha}-p_{m} \frac{d x_{m}}{d \alpha}=\left(h^{\prime}-p_{m}\right) \frac{d x_{m}}{d \alpha} .
$$

Recalling the equilibrium price previously defined as $p_{m}=\alpha h^{\prime}\left(x_{m}(\alpha)\right)$, the above expression can be rewritten as

$$
\frac{d C_{m}}{d \alpha}=(1-\alpha) h^{\prime} \frac{d x}{d \alpha},
$$

where $d x / d \alpha=-h^{\prime}(x) / \alpha h^{\prime \prime}(x)>0$. We observe that the monopolistic consumer surplus is decreasing in the magnitude of the externality $(1-\alpha)$, as the social marginal utility is larger than the individual marginal utility. ${ }^{20}$ To study the externality effects on the competitive consumer surplus, we adopt the same type of analysis. Then, taking the derivative of Eq. (17) with respect to $\alpha$, it results that the competitive consumer surplus is decreasing in $1-\alpha$ as well ${ }^{21}$

$$
\frac{d C_{c}}{d \alpha}=h^{\prime} \frac{d x}{d \alpha}-p \frac{d x}{d \alpha}=\left(h^{\prime}-p\right) \frac{d x}{d \alpha}=(1-\alpha) h^{\prime} \frac{d x}{d \alpha}>0 .
$$

\footnotetext{
${ }^{20}$ Recall that $h^{\prime}$ represents the social marginal utility from the consumption of health.

21 That said, we need to distinguish goods invented before and after $t=0$, because the production realized before $t=0$ yields some exogenous surplus that is affected by the new patent regime.
} 
Considering both consumer surplus types, its total is equal to:

$$
C_{m} \Omega+C_{c}(\bar{T}-\Omega)
$$

where $\bar{T}=\left(1-e^{-\rho \bar{\tau}}\right) / \rho$. From above we have that the total discounted surplus is given by the sum of the surplus from the consumption of the monopolistic good and of the surplus from the consumption of the good bought at a competitive price. Recalling Eqs. (1),(3), and $E=w\left(L-L_{R}\right)+n_{m} M \pi$, and assuming that the new goods are introduced in the market at a constant rate $(\phi)$ after time 0 , the government's maximization problem can be defined as

$$
\max _{\Omega}\left\{W(0)=\Lambda_{0}+\frac{w\left(L-L_{R}\right)}{\rho}+\frac{M \phi}{\rho}\left[C_{m}(\alpha)+\pi(\alpha)\right] \Omega+\frac{M \phi}{\rho} C_{c}(\alpha)(\bar{T}-\Omega)\right\},
$$

where $\Lambda_{0}$ is the discounted present value of the consumer surplus along with the profits derived from goods invented before $t=0$. According to our formulation of the welfare function, we expect to find a trade-off between the benefits of reducing the monopolistic inefficiency and the need to stimulate investments in innovation. Our purpose is to pin down the optimal patent policy $\Omega$ in the presence of a health externality. Correction of this market failure requires a reduction in the patent length, whereas innovation incentives for the identification of new drugs call for a strengthening of patent protection. Recalling the production function defined in Eq. (6), where the equilibrium $L_{R}$ is a function of $\Omega$, and combining Eqs. (9), (10) and (14), we obtain the equilibrium monetary wage level

$$
\Omega M \pi(\alpha) F_{L}\left(L_{H}, L_{R}\right)=w .
$$

This last equations states that the marginal productivity of human capital invested in $R \& D$, expressed in terms of the patent value, is equal to the monetary wage. ${ }^{22}$

Now we have all the ingredients to determine the optimal patent policy in a closed economy. Notice that the aggregate welfare in Eq. (21) depends both on the heath externality effect and on the index of patent protection. In this framework patent length and enforcement are treated as perfect substitute in defining a IPRs regime. After introducing the equilibrium level of $L_{R}$ as function of $\Omega$, the welfare to be maximized can be written as: ${ }^{23}$

$$
\begin{aligned}
\rho W(0)= & \rho \Lambda_{0}+w\left[L-L_{R}(\Omega)\right] \\
& +M F\left(L_{H}, L_{R}(\Omega)\right)\left\{\left[C_{m}(\alpha)+\pi(\alpha)-C_{c}(\alpha)\right] \Omega+C_{c}(\alpha) \bar{T}\right\},
\end{aligned}
$$

from which the first-order condition is

$$
\begin{aligned}
& M F\left(L_{H}, L_{R}(\Omega)\right)\left[C_{c}(\alpha)-C_{m}(\alpha)-\pi(\alpha)\right] \\
& \quad=M F_{L_{R}}^{\prime}\left\{\left[C_{m}(\alpha)+\pi(\alpha)-C_{c}(\alpha)\right] \Omega+C_{c}(\alpha) \bar{T}\right\} L_{R}^{\prime}-w L_{R}^{\prime} .
\end{aligned}
$$

\footnotetext{
${ }^{22}$ Equation (22) gives us the opportunity to uncover the functional relationship between the labour devoted to R\&D and the policy variable $\Omega$, by differentiation we get $M \pi(\alpha) F_{L} d \Omega+M \pi(\alpha) \Omega F_{L L} d L=0$. From this latter expression we obtain $\frac{d L_{R}}{d \Omega}=-\frac{M \pi F_{L}\left(L_{H}, L_{R}\right)}{M \pi \Omega F_{L L}\left(L_{H}, L_{R}\right)}>0$.

23 See the "Appendix" for details.
} 
This last equation reveals how the effect of an increase in $\Omega$ is influenced by the magnitude of the externality. A greater patent protection raises the monopoly power reducing the output volume, but at the same time, it expands the varieties of available goods. What emerges clearly is that the optimal patent policy depends in a complex fashion on the functional forms and on the parameters of the model. The crucial aspects of the model, especially the relation between $\Omega^{*}$ and the health externality, can be better highlighted by using a numerical simulation. For this purpose we calibrate the model along the lines of the existing literature.

Consistently with Ginarte and Park (1997), we acknowledge that a country's level of development in research activities and the market structure are among the most important factor in the definition of the patent protection level. A numerical exercise allows us to study how the optimal patent policy changes as we vary the parameters' values, and how the social welfare is affected accordingly. Assuming a market size of 100 , we initially set the number of skilled and unskilled workers employed in the innovative sector two equal to $60 \%$ and $40 \%$ of the size of our economy, respectively. We define a unitary production coefficient, $a=1$, which corresponds to the level of technology employed in the production process of the innovative sector, and analogously the number of inputs needed to produce 1 unit of the homogenous good in sector one. To reflect how the level of R\&D available in the country determines the optimal patent policy, the share parameter $b$ assumes alternatively values equal to $0.2,0.5$ and 0.8 . Enforcement is clearly an important feature of the patent policy, and at a first stage we assume that, regardless of the size of the economy the government sets alternatively $\omega=0.1,0.5,1$. The annual rate of discount is constant and set equal to $\rho=0.04$. Table 1 reports the calibration of the model under the hypothesis that the individual utility function is given by

$$
h[x(i)]=\frac{x(i)^{1-\sigma}-1}{1-\sigma},
$$

which, following the consumer's equilibrium defined in Eq. (5), implies a consumer demand equal to $x=(\alpha / p)^{1 / \sigma}$, where the inverse elasticity of intertemporal substitution is described by $\sigma>0 ; \sigma \neq 1$.

We report in Fig. 1 the relationship between the optimal patent policy, expressed by the patent-length under the assumption of a specific enforcement level, and the level of health externality, where we vary pivotal parameters of our closed economy, i.e. clockwise: consumers size, share parameter of the production function, patent protection enforcement policy (probability), and responsiveness of the growth rate of consumption.

Figure 1a shows how the optimal patent protection is related to the magnitude of the health externality. According to our numerical simulation this relationship is positive, which means that the optimal patent length is increasing in the health externality, $1-\alpha$. In other words, to maintain a high state of social health, governments should guarantee and preserve the exclusivity of patents' owner right, in order to motivate further advancement in new drugs discovery. As expected, for different values of consumers size, $M$, the optimal patent policy changes considerably, highlighting the importance of the size of the economy. For any 
magnitude of the health externality below 0.67 , the best patent policy is decreasing in the size of the country. Indeed, it varies from a minimum level of 1 year to the maximum level of 20 years, which has been imposed as a ceiling.

From this analysis it becomes clear how, in a closed economy in which we do not take other endogenous effects into account, fixing a priori the duration of the patent protection at 20 years is not optimal. Changing the amount of the unskilled workers employed in the economy $\left(L_{H}\right)$, like varying the labour productivity, yields no significant difference in terms of optimal patent policy. Conversely, a shift in the relative weight of skilled labour with respect to the unskilled one in the production function $(b)$ alters the optimal patent length substantially (see Fig. 1b). This means that a country's level of research and development activity influences the optimal length of patent protection. The larger is the quota of skilled workers, the lowest should be the time-patent length. In Fig. 1c, we change the level of effort that the government is able to apply on the enforcement of the IPRs regime, as measured by the index $\omega$. At any given level of $1-\alpha$, the greater is the enforcement effort of the government, the lower the optimal patent length. Intuitively, in a country where the legal enforcement matters, the optimal timelength of the patent's owner exclusive right can be reduced. In other words, when innovators can be reassured that any unauthorized agent will not be able to use their innovation, the returns on investment in $R \& D$ are guaranteed in a shorter period of time. The implications of different values of $\sigma$, which is the inverse of the intertemporal elasticity of substitution are displayed in Fig. 1d. A low level of $\sigma$, that is a high intertemporal elasticity, entails a patent protection extended to the maximum, for most levels of the health externality. It follows that goods characterized by a low intertemporal elasticity (e.g. drugs for infectious diseases) call for a limited period of IPR protection. This would mean that in front of a health emergency, it would be optimal to reduce the time-length of the patent's owner exclusivity so that drugs can be produced on a larger scale without restrictions, allowing a broader group of the population to have access.

\section{Global patent protection}

In this section, by opening up the economy to the rest of the world, we present an extension of the previous closed economy model in order to evaluate the magnitude of the strategic interaction between two countries which are interlinked between them. In particular, in a world characterized by imitation and trade and affected by health externalities, we want to study governments' national incentives to adopt IPR policies. It is well established that at an international level a fundamental tension exists between the social desiderability of widespread dissemination of available knowledge and the need to provide adequate rewards to the suppliers of new inventions. In light of this contention, we investigate how the absence of an international agreement on patent protection can affect the global welfare, when this knowledge base gives the opportunity to preserve an important global public good: public health. 
Table 1 Baseline calibration in a closed economy
Inverse elasticity of intertemporal substitution

Discount rate

Enforcement policy (probability)

Amount of unskilled labor

Consumers size

Measure of labor productivity

Share parameter

Patent duration (years)

$$
\begin{aligned}
& \sigma=0.2,0.5,0.7 \\
& \rho=0.04 \\
& \omega=0.1,0.5,1 \\
& L_{H}=40 \\
& M=100 \\
& a=1 \\
& b=0.2,0.5,0.8 \\
& \bar{\tau}=20
\end{aligned}
$$

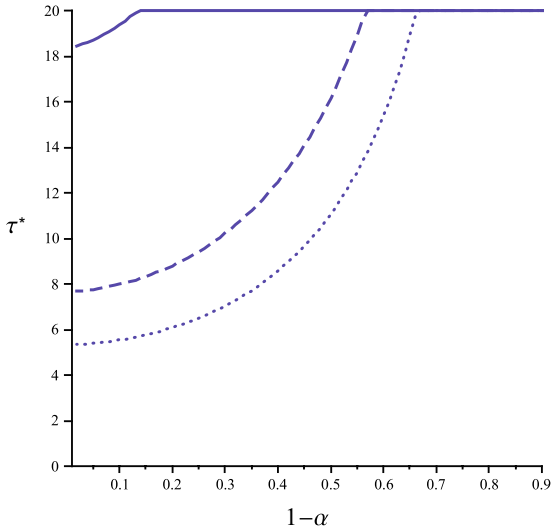

.... Large economy - - Medium economy — Small economy

(a)

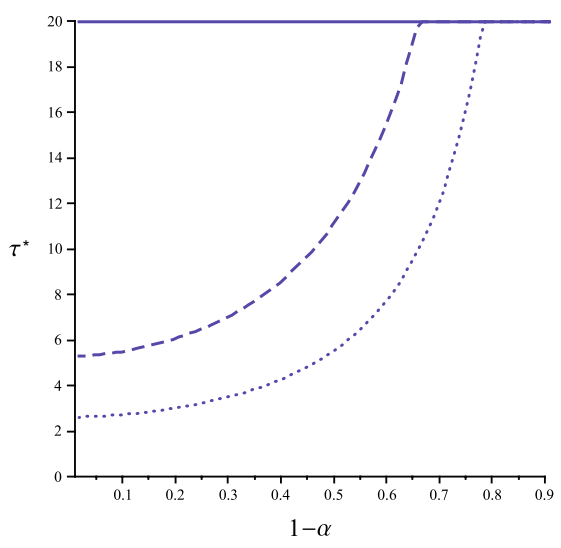

(c)

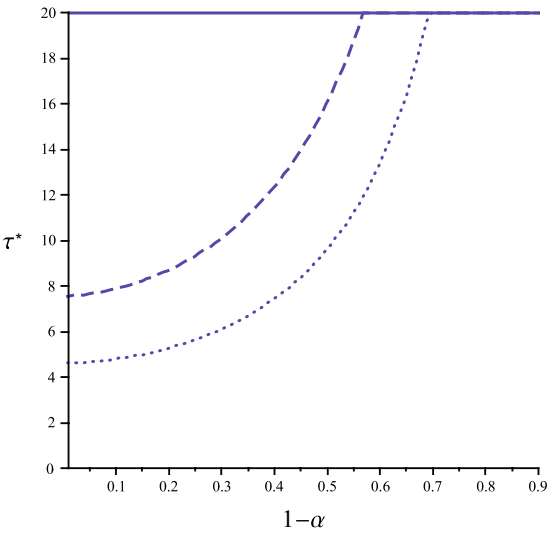

$\cdots b=0.8--b=0.5-b=0.2$

(b)

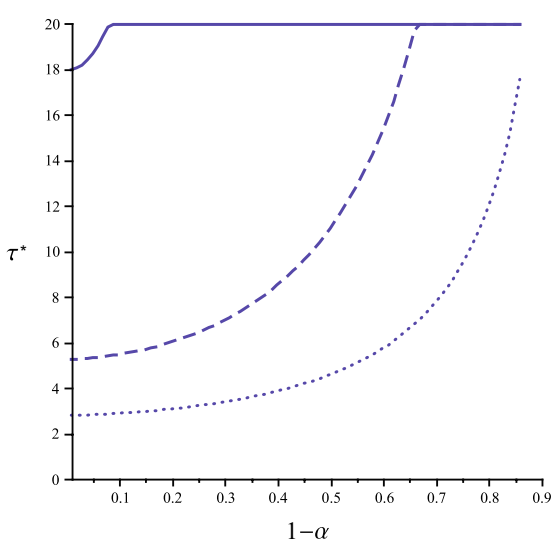

$\cdots \sigma=0.7--\sigma=0.5-\sigma=0.2$

(d)

Fig. 1 Optimal patent policy in a closed economy 


\subsection{The IPR system at a global level}

Consider a world with two countries: the North and the South (or the East and the West) where each country's public health depends on the country's own health externality. Under the assumption that the innovation process occurs in the North, we want to evaluate the influence of the Southern externality on the North's optimal patent policy, and vice versa. In particular, we first seek to identify the optimal patent policy, under the assumption that the health externality is confined to the single countries. Afterwards, we move our analysis towards an investigation of the cross effects of the two health externalities. In order to find the equilibrium we build a game in which: the two countries (the North and the South) are the two players; both countries set their own patent policies simultaneously following a non-cooperative strategy. The North and the South differ in some aspects of the economy: their wages rate, their market size, their stock of human capital, and in particular their health externality. However, in both countries (1) consumers have identical preferences; (2) the representative consumer maximizes her intertemporal utility function; which (3) at a certain point on time, for country $\kappa$ is defined as

$$
U_{\kappa}(t)=c_{\kappa}(t)+v_{\kappa}\left(H_{\kappa}, \overline{H_{\kappa}}\right), \quad \text { where } \kappa=N, S,
$$

where $c_{\kappa}(t)$ is the utility enjoyed from consuming the homogeneous good for an individual resident in country $\kappa$ at time $t$. Whereas, like in the previous section, $v_{\kappa}$ is the consumer's subutility deriving from the individual level of health, $H_{\kappa}$, and the social health level $\bar{H}_{\kappa}$ in each country. As in Eq. (2) of the previous section, the consumer subutility coming from the health sector take the following Cobb-Douglas form:

$$
v_{\kappa}\left(H_{\kappa}, \bar{H}_{\kappa}\right)=H_{\kappa}^{\alpha_{\kappa}} \bar{H}_{\kappa}^{1-\alpha_{\kappa}}, \quad \text { with } 0<\alpha_{\kappa}<1 .
$$

Again, we assume that the individual's utility depends on both the individual personal consumption of drugs and the social health level. By the health externality $\left(1-\alpha_{\kappa}\right)$, we measure the advantage (or disadvantage) for a consumer of living in country $\kappa$. We define $H_{\kappa}$ as the total utility obtained by consuming a bundle of pharmaceutical products available in the $\kappa$ economy

$$
H_{\kappa}=\int_{0}^{n_{S}(t)+n_{N}(t)} h\left[x_{\kappa}(i, t)\right] d i,
$$

where $h(x)$ is the subutility derived from the consumption of a single pharmaceutical product; $x_{\kappa}(i, t)$ represents the consumption of the $i$ th variety of the differentiated pharmaceutical products at time $t ; n_{S}(t)$ and $n_{N}(t)$ indicate the number of those differentiated pharmaceutical products introduced and manufactured respectively in the South and in the North before $t$, which still have a value for consumers at time $t$. The market size of the two countries is denoted by $M_{N}$ and $M_{S}$, and by assumption both countries are affected by their own externality, $\left(1-\alpha_{\kappa}\right)$, with $\kappa=S, N$. After examining the case where both countries have equal market size, we deal with the scenario where having a different number of consumers influences government's 
decisions over the patent policy. Like in the previous section, the production of new goods at time $t$ is described in each country by the following CES function

$$
\phi_{\kappa}(t)=F\left[L_{H_{\kappa}}, L_{R_{\kappa}}(t)\right]=\left\{b\left[L_{R_{\kappa}}(t) / a_{\kappa}\right]^{\beta}+(1-b) L_{H_{\kappa}}^{\beta}\right\}^{1 / \beta},
$$

where $L_{H_{\kappa}}$ is the human capital endowment of country $\kappa$ employed in the manufacturing sector; $L_{R_{\kappa}}$ is the labour devoted to R\&D sector; $1 / a_{\kappa}$ indicates labour productivity. ${ }^{24}$ Now we have all the main elements to describe the IPR regime. What needs to be underlined here is that in both countries holds the principle of the "national treatment" ${ }^{25}$ This entails government of country $\kappa$ to enforce the same degree of protection to all inventors of differentiated products, without discriminating according to the firms' nationality. Foreign and domestic firms have equal opportunity in applying for patents in any country and all patents are subject to the same enforcement conditions. This approach is justified by the actual harmonization of the patent policies at international level, as result of the TRIPs agreement. ${ }^{26}$

As before, patent protection is measured by $\Omega_{\kappa}=\omega_{\kappa} T_{\kappa}$, where $\omega_{\kappa}$ is the probability that a patent is enforced in country $\kappa$ at any moment in time (or the fraction of the market in which a patent is enforced), with $T_{\kappa}=\left(1-e^{-\rho \tau_{\kappa}}\right) / \rho$ and $\tau_{\kappa}$ representing the length of a patent granted by country $\kappa$. Adopting a standard approach, we assume that the patent holder has the exclusive right to use an invention for a specific period of time. During that period the monopolistic firm is allowed to produce and sale for the domestic market and to satisfy the foreign demand. At the same time, any unauthorized imports of the protected goods is unlawful. In order to study the behavior of the two governments in setting their patent policy, we have to solve a strategic game in which at $t=0$, the government applies the protection on the invented goods guarantying that right until time $\tau$. In the meantime, goods invented before $t=0$ continue to receive the same protection enforced from the time of their invention.

\subsection{The welfare in an open economy}

Like in G\&L, in the current analysis the identification of the optimal patent policy lies on the Nash equilibrium, which is also subgame perfect in the infinitely repeated game. Once the patent policy has been employed, indeed, it is not possible to revoke

\footnotetext{
${ }^{24}$ Initially, we assume that $a_{S}<a_{N}$, which means that labour is uniformly more productive in the North than in the South, whereas to study the welfare effects yielded by a global patent policy we impose $a_{S}=a_{N}$ in the numerical simulation. Moreover, we assume that the homogeneous good, which is also the numéraire, is produced in positive quantities in both countries, in order to guarantee that $w_{\kappa}=1 / a_{\kappa}$. If $a_{S}<a_{N}$, clearly we have that $w_{N} / w_{S}=a_{N} / a_{S}>1$..

25 According to the WTO, imported goods must have the same treatment as the locally-produced ones, at least after they have entered the market. The same rules hold for services trademarks, copyrights and patents.

${ }^{26}$ As we discussed in the introduction, the TRIPs agreement was the first multilateral trade accord that has represented a major turning point in the protection of intellectual property rights at global level (Maskus 2000).
} 
all the patents that have been granted in the past periods. We refer to the patent policies of the two countries as $\Omega_{N}$ and $\Omega_{S}$. Recalling Eqs. (13) and (14), we assume that patent enforcement is given, so that we focus our attention on the patent length, $\tau$. The patent holder earns an expected flow of profits equal to $\pi \omega_{N} M_{N}$ from the Northern market, and $\pi \omega_{S} M_{S}$ from the Southern market. Since we assume that consumers have the same type of preferences in both countries, we observe that the profit per consumer achievable in each country by the monopolistic firm is also the same. ${ }^{27}$ Considering the two types of good, the monopolistic and the competitive one, the expected surplus that a single consumer enjoys is given by the following expression $^{28}$

$$
\Omega_{\kappa} C_{m}\left(\alpha_{\kappa}\right)+\left(\bar{T}-\Omega_{\kappa}\right) C_{c}\left(\alpha_{\kappa}\right) .
$$

According to the TRIPs agreement, we know that after a period of 20 years, patent protection will expire. Assuming that no international exhaustions are in force, if a patent expires in the South, its price becomes competitive only in the local market where both Southern and Northern firms sell their own products, while the same good is still protected by the patent in the North.

When a patent expires in the South, the price of the good falls from $p_{m}$ to $p_{c}=w_{S} a_{S}=1$ and the flow of the consumer surplus for that good in the South rises to $M_{S} C_{c}\left(\alpha_{S}\right)$. When the patent expires also in the North, its market can be served by competitive firms producing in both locations and the original inventor loses her remaining monopoly income. Obviously, as in the South, also in the North the price falls to $p_{c}=w_{N} a_{N}=1$, triggering a higher flow of consumer surplus equal to $M_{N} C_{c}\left(\alpha_{N}\right)$. After $\bar{\tau}$ periods elapse, the good becomes obsolete and the flow of consumer surplus ceases.

\subsection{The Nash equilibrium in an open economy}

To solve for the Nash equilibrium of our simultaneous-move game, we compute the best response function of both countries. Each best response is obtained by maximizing the national welfare, and it expresses the degree of patent protection, for a given level of enforcement, as a function of the analogous policy in the other country. Under this scenario, the decision taken by each government in their own country conditions not only the optimal IPR regime launched domestically, but also the policy introduced by their trade partners. It should be highlighted that both the patent policy and the health externality of the other country affect the domestic welfare of each country. If we analyse the North's maximization problem, given the choice of the Southern government $\Omega_{S}$, we can distinguish two different costs from an enhancement of the IPR. An increase of

\footnotetext{
27 This is a simplifying assumption, as we are aware that consumption preferences are unlikely to be the same in the South and in the North. Most diseases that afflict less developed countries do not exist in developed economies (i.e. neglected diseases).

${ }^{28}$ Like in G\&L we suppose that consumers preferences are not affected by the productivity gap, so that the price of the patented good is independent of where it was invented and where the production was realized. The rest of the assumptions are the same as in Sect. 3.
} 
the patent length affects firstly all goods invented in the past for which the protection time is now larger, and so the time during which the economy suffers a deadweight loss equal to $M_{N}\left[C_{c}\left(\alpha_{N}\right)-C_{m}\left(\alpha_{N}\right)-\pi\left(\alpha_{N}\right)\right]$. Secondly, the same loss involves those goods invented in the South but excluding the profits, which belong to inventors located in the South. For each of these goods the cost is equal to $M_{N}\left(C_{c}-C_{m}\right)$. Let us now define the best response functions of the Northern and the Southern governments. The discounted welfare function of the North at time $t=0$ is defined as follows

$$
\begin{aligned}
W_{N}(0)= & \Lambda_{N 0}+\frac{w_{N}\left(L_{N}-L_{R N}\right)}{\rho} \\
& +\frac{M_{N}\left(\phi_{S}+\phi_{N}\right)}{\rho}\left[\Omega_{N} C_{m}\left(\alpha_{N}\right)+\left(\bar{T}-\Omega_{N}\right) C_{c}\left(\alpha_{N}\right)\right] \\
& +\frac{\phi_{N}}{\rho} \pi\left(\alpha_{N}\right)\left(M_{S} \Omega_{S}+M_{N} \Omega_{N}\right) .
\end{aligned}
$$

Before proceeding to solve the maximization problem, it is useful to identify which variables are affected by $\Omega_{N}$. In fact, some variables, such as $L_{R N}$, depend directly on $\Omega_{N}$, whereas some others, as $\phi_{N}$, do so only indirectly. At this stage it is important to highlight our main assumptions. Firstly, we take for granted that the numéraire good is produced in positive quantities in both countries, so as to have a wage level in the North equal to $w_{N}=\frac{1}{a_{N}}$. Secondly, the volume of labour employed in the research sector in the North is a function of $\Omega_{N}$. Finally, with reference to the production function, new goods are invented in each region according to the production function defined in Eq. (6), where the first derivative with respect to $\Omega_{N}$ amounts to $\phi_{N}^{\prime}\left(\Omega_{N}\right)=\frac{F_{L} L_{R N}^{\prime}}{a_{N}}$. Given these considerations, we can rewrite the welfare function at $t=0$ as follows

$$
\begin{aligned}
\rho W_{N}(0)= & \rho \Lambda_{N 0}+\frac{1}{a_{N}}\left(L_{N}-L_{R N}\left(\Omega_{N}\right)\right) \\
& +M_{N}\left(\phi_{S}+\phi_{N}\left(\Omega_{N}\right)\right)\left[\Omega_{N} C_{m}\left(\alpha_{N}\right)+\left(\bar{T}-\Omega_{N}\right) \times C_{c}\left(\alpha_{N}\right)\right] \\
& +\phi_{N}\left(\Omega_{N}\right) \pi\left(\alpha_{N}\right) \times\left(M_{S} \Omega_{S}+M_{N} \Omega_{N}\right) .
\end{aligned}
$$

Given our hypothesis of symmetric countries, the reaction function of both players is identical, and computed for the North it is defined as:

$$
\begin{aligned}
\Omega_{N}= & -\frac{\gamma C_{c}\left(\alpha_{N}\right) \bar{T}}{\left(C_{m}\left(\alpha_{N}\right)-C_{c}\left(\alpha_{N}\right)\right)(\gamma-1)+\mu_{N} \pi\left(\alpha_{N}\right)} \\
& +\frac{C_{c}\left(\alpha_{N}\right)-C_{m}\left(\alpha_{N}\right)-\mu_{N} \pi\left(\alpha_{N}\right)}{\left(C_{m}\left(\alpha_{N}\right)-C_{c}\left(\alpha_{N}\right)\right)(\gamma-1)+\mu_{N} \pi\left(\alpha_{N}\right)} \Omega_{S} .
\end{aligned}
$$

where $\gamma=-F_{L}^{2} /\left(F F_{L L}\right)$ and $\mu=\phi_{N} /\left(\phi_{N}+\phi_{S}\right)$. Since the optimal patent policy depends on the parameters of the model in a complex fashion, it is useful to study 
how the equilibrium depends on the fundamental parameters of the economy by examining a numerical simulation. The calibration of the model is carried out using the values reported in Table 2. This numerical exercise allows us to describe how the welfare of an open economy is affected not only by its own IPRs and the level of the domestic health externality, but also by the policy choices of its trading partners. By identifying the magnitude of the effects yielded by the introduction of a new IPR regime, we aim to study the implications of a global patent regime that covers both the North and the South, for the national welfare.

The results of our simulations are depicted in Figs. 2 and 3, where we represent the optimal patent policy for the North and the South, in relation to the Southern health externality, and the market size of their countries' trade partners, respectively. More specifically, Fig. 2a shows the optimal patent policy in each country for different levels of the Southern externality, when the North does not present any externality at all. The optimal patent protection in both countries increases, as $1-\alpha_{S}$ gets larger, and as expected the South moves at a greater speed. Moreover, it seems that when the health externality is negligible in both countries the best action is to almost abandon the IPR law (both curves start at $\tau^{*}=3$ ). These results do not change when we allow for a larger market size in the North than in the South, with the curves starting at a slightly higher level. This means that the effects of the health externality prevail over those of market size. In order to measure which effect is dominant between health externality and market size we also plot the case where the market in the North is ten times bigger than that of the South. Also in this case, when $\left(1-\alpha_{N}\right)=0$, the result does not change. Conversely, assuming $M_{S}=500$ and $M_{N}=50$, we get that the optimal patent length follows an identical path in the two countries. Hence, a small Northern economy with no health externality will choose the same patent protection as a large Southern economy affected by health externality. This case is depicted in Fig. 2 b.

The scenario is somewhat different when there is a positive value of the health externality in the North. Figure $2 \mathrm{c}$ shows this case. Starting from a level of externality equal to 0.5 in both countries, we notice that $\tau^{*}$ increases as $1-\alpha_{S}$ gets bigger, and under this specific scenario it is greater in the South than that in the North, as in Fig. 2a. Instead, for lower level of $1-\alpha_{S}$ the optimal patent protection in the North is greater. The result does not change much when the market in the North is bigger than that in the South. Assuming identical externality in the two countries, which means the level of good health is the same in both markets and equal to 0.5 , we now study the dynamics of $\tau_{N}^{*}$ and $\tau_{S}^{*}$ when $M_{N}$ increases. To do that we set the size of the Southern market to be always larger than that in the North, specifically $M_{S}=100$. As shown in Fig. 2d, in this case, the optimal patent protection both in the North and in the South is decreasing in the size of the Northern market. These results confirm what our simple closed economy model has proved before. For limited sizes of $M_{N}$, the optimal patent length for the North can reach 18 years and more whereas, when $M_{N}$ approaches the same size of the Southern market, the optimal length remains below the 10 years level. In other words, for large economies to keep the same level of good health the optimal patent policy should not be too long. This means that the exclusive right recognized to the patent's holder will cease earlier leaving the production of drugs free from any formal legal constraints. Hence, the manufacturing of 
Table 2 Baseline calibration in open economy

\begin{tabular}{ll}
\hline Inverse elasticity of intertemporal substitution & $\sigma=0.3,0.5,0.6$ \\
Discount rate & $\rho=0.04$ \\
Enforcement policy (probability) & $\omega_{N, S}=0.5$ \\
Amount of unskilled labor & $L_{H_{N, S}}=40$ \\
Consumers size & $M_{N, S}=25,50,100$ \\
Measure of labor productivity & $a_{N, S}=1$ \\
Share parameter & $b=0.7$ \\
Patent duration (years) & $\bar{\tau}=20$ \\
\hline
\end{tabular}

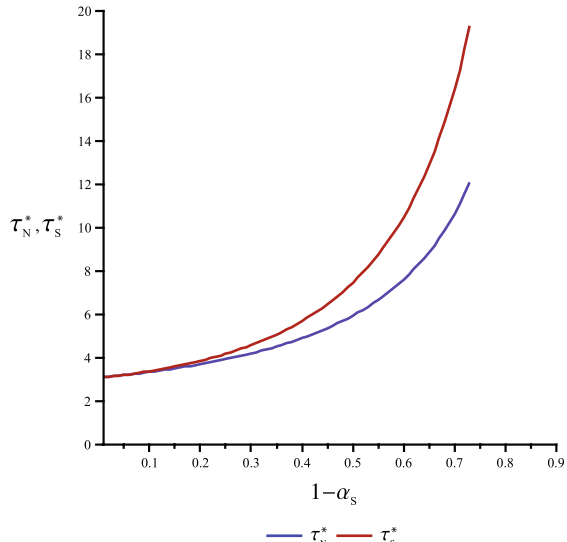

(a)

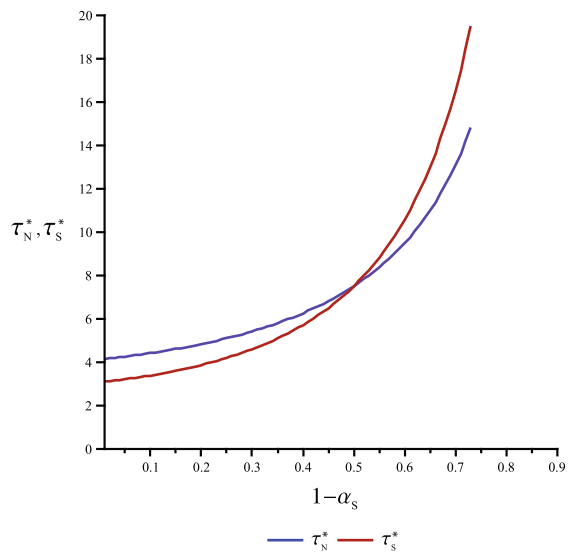

(c)

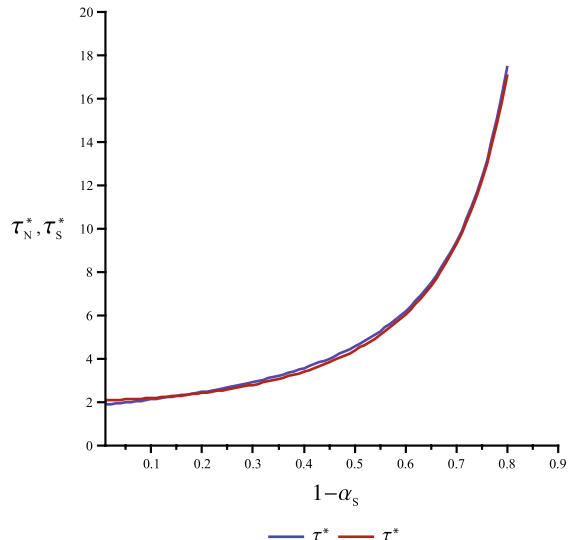

(b)

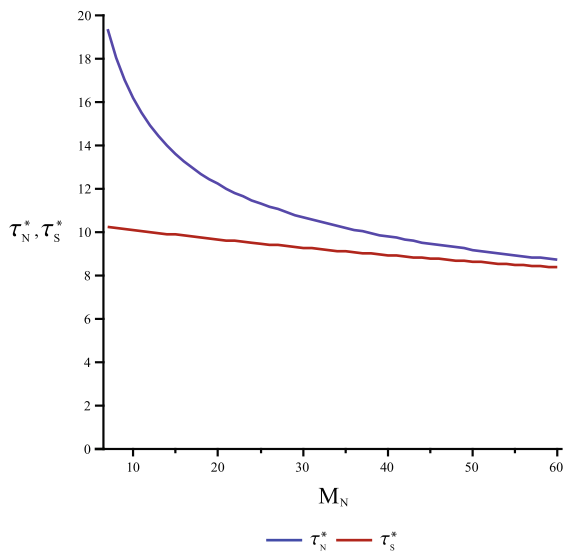

(d)

Fig. 2 Optimal patent policy in open economy I

the drugs will occur under a regime of perfect competition, broadening their access to a larger quota of the population. We have also studied differences in the labour productivity of the two countries, and the results confirm those obtained in the close 


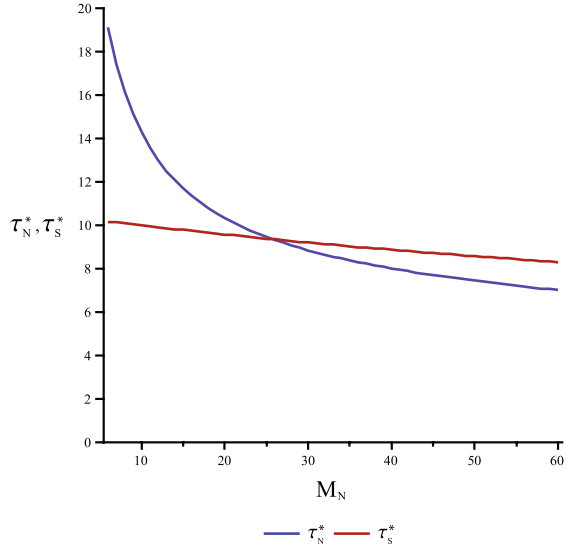

(a)

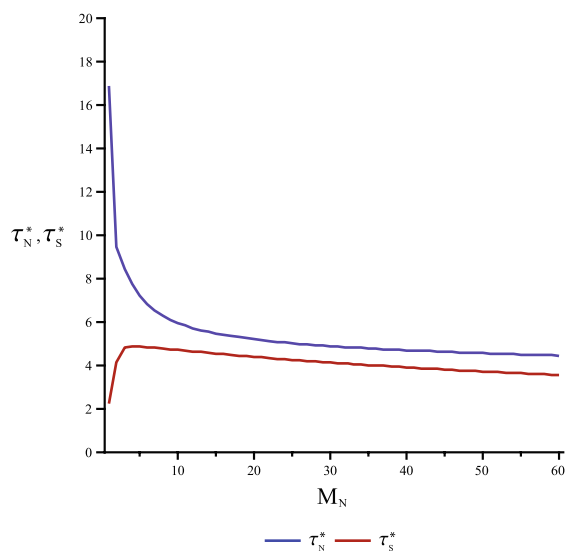

(c)

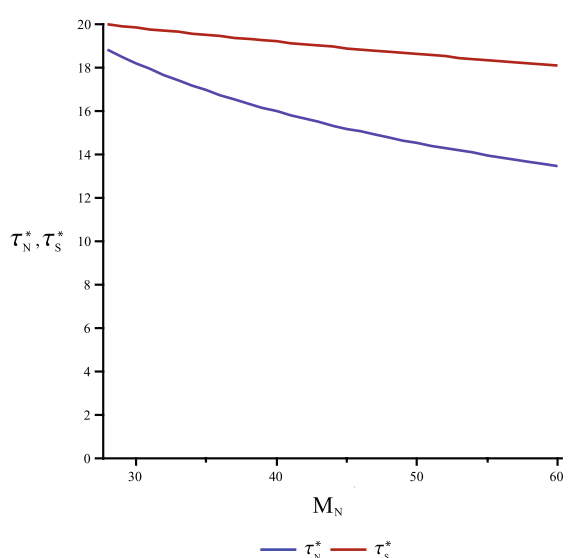

(b)

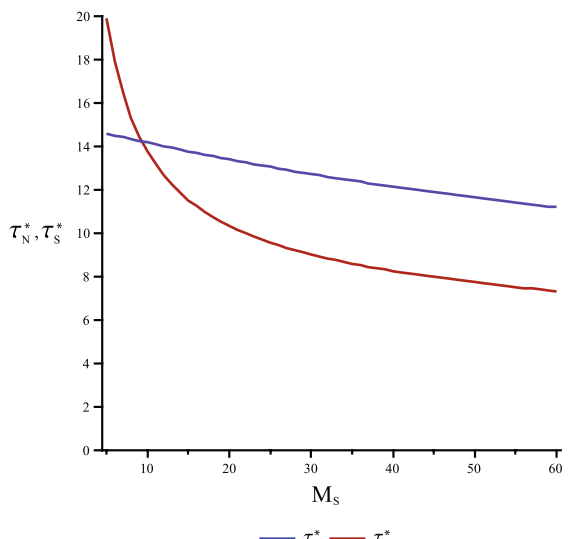

(d)

Fig. 3 Optimal patent policy in open economy II

economy scenario: the larger the quota of skilled workers, the lower should be the optimal time-patent length. Vice versa, more time is needed when the number of skilled workers is limited. These results are robust to differences in the market sizes of the two countries, and to inequalities in the dimension of the health externality (see Fig. 4 in the "Appendix").

Results are different when the state of social health in both countries is different, namely $\left(1-\alpha_{N}\right) \neq\left(1-\alpha_{S}\right)$. Figure 3 a displays the case of $\left(1-\alpha_{N}\right)=0$ and $\left(1-\alpha_{S}\right)=0.5$. Here, the patent length declines faster in the North as $M_{N}$ increases and goes below that of the South after $M_{N}=25$. Enlarging the externality gap between the two countries, we find that the patent length of the North is always smaller, for any market size, whereas when the health externality matters, the Southern government applies a strict patent policy (Fig. 3b). Hence, when we take into account the role played by the health externality, in the country where the state of 
good health is important, governments tend to be cautious, by guaranteing a timelength on the exclusive IPR longer than the case where the health externality has no capacity. If we assume $\left(1-\alpha_{S}\right)=0$ and $\left(1-\alpha_{N}\right)=0.5$, an opposite path emerges between the North and the South (Fig. 3c). For low levels of $M_{N}$ an increasing level of patent protection emerges in the South as the market size of the North grows, while the opposite happens in the North.

Allowing for a difference in the intertemporal elasticity of substitution between the two countries, $1 / \sigma$, we have that the optimal patent length is significantly lower in the country where $1 / \sigma$ is small, confirming to a greater extent the results reached in the closed economy case. Figure $3 \mathrm{~d}$ shows a realistic case in which the North, whose economy is bigger, is characterized by a high inverse intertemporal elasticity of substitution $\left(\sigma_{N}=0.3\right)$ and a low health externality $\left(1-\alpha_{N}=0\right)$, while conversely the South features a low inverse intertemporal elasticity of substitution $\left(\sigma_{S}=0.6\right)$ and social health receives a high weight $\left(1-\alpha_{S}=0.6\right)$ is given. As $M_{S}$ grows, both patent policies require a diminishing length, but this reduction is stronger in the South, implying that the lower intertemporal elasticity in the South seems to override the effect of the higher externality. In other words, in the presence of outbreak diseases, governments should be more lenient on the extent of the exclusive IPR, shortening the length of the patent's holder monopoly power. It seems that when the state of social health is at stake, static efficiency shows a level of greater importance compare to dynamic efficiency. Hence, to keep high the degree of good health, governments should make the consumption of the current available medicines easier.

\section{Conclusions}

Assessing the role played by the new international patent policy, this paper proposed a welfare analysis which reassessed the length and breath of the exclusive right over the intellectual property (i.e. patent), taking into account the effects on the health sector. To this end, we have extended the set-up developed by Grossman and Lai (2004) by including the health sector. We have taken into account the incentives that a government has, by introducing the IPRs, when the utility of agents depends on the consumption of pharmaceutical goods and on the level of social health in the whole economy. We investigated the traditional trade-off where the presence of an intellectual property right regime is vital to guarantee the private incentives to invest in $\mathrm{R} \& \mathrm{D}$, but when too stringent a deadweight loss can reduce the level of the social health, generating detrimental effects.

This paper has shown that the socially optimal patent protection is strictly correlated to the health externality. Specifically, according to our numerical results this relation is positive: the optimal patent length is increasing in the magnitude of the health externality. We know that an increased patent protection has two opposing effects: on the one hand it induces a higher flow of new goods. On the other hand, it worsens the deadweight loss coming from the monopoly market yielded by the presence of IPRs. When the social health has a high weight in the individual's utility, 
a longer patent life seems to be the consequence of the fact that positive dynamic effects dominate static inefficiencies.

Moreover, we have found that in a closed economy analysis, the size of the market plays a relevant role, namely the larger the number of consumers the shorter the optimal patent length. Moreover, for goods with a low price elasticity (e.g. drugs for infectious diseases) it is optimal to reduce the patent-length. When the size of the health externality is connected with the individual consumption of pharmaceutical goods, the identification of the optimal patent protection is crucial for social welfare. When we move to a global perspective, we discover that the social welfare of each country is affected indirectly by the patent policy applied by its trading partner. We have also found that, for high levels of health externality in the South and average levels in the North, the optimal patent protection in both countries is always below the minimum required by the actual intellectual property right law (20 years). These results are unaffected by the size of the Northern economy. Indeed, this outcome is confirmed when the Northern economy is bigger than or equal to the Southern economy. Our results confirmed the contention that IPR policy has significant implications on the global welfare level.

It is important to mention that the market for technology has increased substantially in recent years. In our current analysis we do not include these aspects, remaining agnostic on the role played by licensing and IP agreements, which recently have turned to be a valid and widely adopted tool among competitors. Moreover, as for patents, also announcements of new discoveries can increase the value of the firm and hence the returns to innovation. When deciding the optimal patent policy, governments should take into account also these important aspects. However, to simplify our analysis we focused only on the optimal patent policy which captures directly both the time-length and breadth of the IPR protection, and indirectly these other new development of the IPR world. An interesting line of research would be to incorporate these other aspects into the analysis, calling for further investigations.

To sum up, what should be highlighted from our analysis is that, when deciding on the optimal patent policy, governments have to take into account the role played by the externalities in social health. In a world with almost no barriers, the policies adopted by their trading partners would generate effects also at the domestic level. Specifically, the presence of the health externality, which is not internalized by the single optimizing individual, calls for the monitoring of pharmaceutical consumption and of collective health by the public authorities.

Finally, it should be recalled that the policy recommendations suggested by our study are relevant for a highly globalized market, such as the pharmaceutical one. Moreover, given the nature of our framework, it is important to mention that where the national health system is publicly funded, governments, as primary customers of pharmaceutical goods, play an important role. Indeed, not only they can decide the optimal patent policy to apply for such products, but they also have the power to improve the state of social health by introducing ad hoc regulation on pharmaceutical products which expands their access. Further research to incorporate the interrelations between patent policy and pharmaceutical price regulation would be worthwhile. 
Acknowledgements We would like to thank Fabrizio Adriani, Barbara Annicchiarico, Vincenzo De Lipsis, Margaret Kyle and Tommaso Valletti for their helpful and constructive suggestions. Comments from seminar participants at University of Rome "Tor Vergata", Collegio Carlo Alberto, Université Montpellier I and School of Oriental and African Studies are gratefully acknowledged. All remaining errors are our own.

Open Access This article is distributed under the terms of the Creative Commons Attribution 4.0 International License (http://creativecommons.org/licenses/by/4.0/), which permits unrestricted use, distribution, and reproduction in any medium, provided you give appropriate credit to the original author(s) and the source, provide a link to the Creative Commons license, and indicate if changes were made.

\section{Appendix}

Recalling the government maximization problem in a closed economy as per Eq. (21), after some manipulations we obtain the government's objective function:

$$
\begin{aligned}
W(0) & =\Lambda_{0}+\frac{w\left(L-L_{R}\right)}{\rho}+\frac{M \phi}{\rho}\left[C_{m}(\alpha)+\pi(\alpha)\right] \Omega+\frac{M \phi}{\rho} C_{c}(\alpha)(\bar{T}-\Omega), \\
\rho W(0) & =\rho \Lambda_{0}+w\left[L-L_{R}(\Omega)\right]+M \phi\left[C_{m}(\alpha) \Omega+\pi(\alpha) \Omega\right]+M \phi\left[C_{c}(\alpha) \bar{T}-C_{c}(\alpha) \Omega\right], \\
\rho W(0) & =\rho \Lambda_{0}+w\left[L-L_{R}(\Omega)\right]+M \phi\left\{\left[C_{m}(\alpha)+\pi(\alpha)-C_{c}(\alpha)\right] \Omega+C_{c}(\alpha) \bar{T}\right\},
\end{aligned}
$$

from which we obtain the first-order condition by imposing $\frac{\partial W}{\partial \Omega}=0$ :

$$
\begin{aligned}
& -w L_{R}^{\prime}+M F_{L_{R}}^{\prime} L_{R}^{\prime}\left\{\left[C_{m}(\alpha)+\pi(\alpha)-C_{c}(\alpha)\right] \Omega+C_{c}(\alpha) \bar{T}\right\} \\
& \quad+M F\left(L_{H}, L_{R}(\Omega)\right)\left[C_{m}(\alpha)+\pi(\alpha)-C_{c}(\alpha)\right]=0, \\
& M F_{L_{R}}^{\prime} L_{R}^{\prime}+\left\{\left[C_{m}(\alpha)+\pi(\alpha)-C_{c}(\alpha)\right] \Omega+C_{c}(\alpha) \bar{T}\right\}-w L_{R}^{\prime} \\
& \quad=M F\left(L_{H}, L_{R}(\Omega)\right)\left[C_{c}(\alpha)-\pi(\alpha)-C_{m}(\alpha)\right], \\
& \left\{M F_{L_{R}}^{\prime}\left[C_{m}(\alpha)+\pi(\alpha)-C_{c}(\alpha)\right] \Omega+C_{c}(\alpha) \bar{T}\right\} L_{R}^{\prime}-w L_{R}^{\prime} \\
& \quad=M F\left(L_{H}, L_{R}(\Omega)\right)\left[C_{c}(\alpha)-\pi(\alpha)-C_{m}(\alpha)\right] .
\end{aligned}
$$

The above expression (A2) can be reformulated in terms of equality between marginal benefits and marginal costs as follows:

$$
\begin{aligned}
M F & \left(L_{H}, L_{R}(\Omega)\right)\left[C_{c}(\alpha)-\pi(\alpha)-C_{m}(\alpha)\right] \\
& =-w L_{R}^{\prime}+M F_{L_{R}}^{\prime} L_{R}^{\prime} \Omega\left[C_{m}(\alpha)+\pi(\alpha)-C_{c}(\alpha)\right]+M F_{L_{R}}^{\prime} L_{R}^{\prime} C_{c}(\alpha) \bar{T}, \\
& =M F_{L_{R}}^{\prime}\left[L_{R}^{\prime} \Omega\left(C_{m}(\alpha)+\pi(\alpha)-C_{c}(\alpha)\right)+L_{R}^{\prime} C_{c}(\alpha) \bar{T}\right]-w L_{R}^{\prime}, \\
& =M F_{L_{R}}^{\prime} L_{R}^{\prime}\left[\Omega\left(C_{m}(\alpha)+\pi(\alpha)-C_{c}(\alpha)\right)+C_{c}(\alpha) \bar{T}\right]-w L_{R}^{\prime}, \\
& =M F_{L_{R}}^{\prime} L_{R}^{\prime}\left[C_{m} \Omega+C_{c}(\bar{T}-\Omega)\right]+L_{R}^{\prime}\left(M F_{L_{R}}^{\prime} \Omega \pi-w\right) .
\end{aligned}
$$



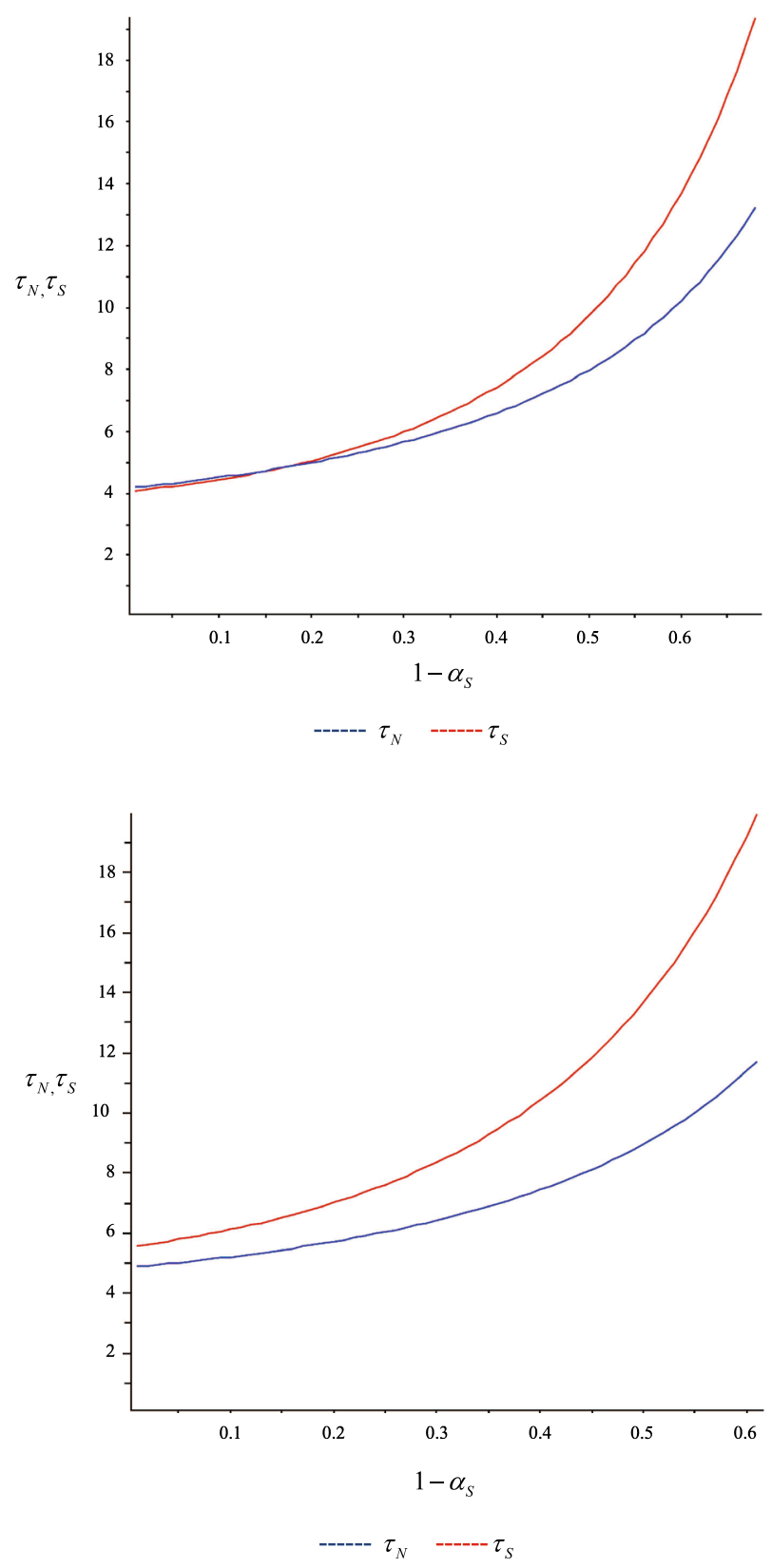

Fig. 4 Optimal patent policy in open economy—different labour productivity

Since $\eta F_{L_{R}}^{\prime}=w$ that is $M F_{L_{R}}^{\prime} \Omega \pi=w$, the above condition becomes:

$$
F\left(C_{c}-C_{m}-\pi\right)=F_{L_{R}}^{\prime} L_{R}^{\prime}\left[C_{m} \Omega+C_{c}(\bar{T}-\Omega)\right] .
$$


Thus, we have:

$$
\frac{d F}{d \eta} \frac{d \eta}{d \Omega}\left[C_{m} \Omega+C_{c}(\bar{T}-\Omega)\right]=F\left(C_{c}-C_{m}-\pi\right),
$$

since $d F / d \eta=\gamma(F / \eta)$, and $\eta=\Omega M \pi$ from which $d \eta / d \Omega=M \pi$, hence

$$
\begin{aligned}
& \gamma \frac{F}{\eta} M \pi\left[C_{m} \Omega+C_{c}(\bar{T}-\Omega)\right]=F\left(C_{c}-C_{m}-\pi\right), \\
& C_{c}-C_{m}-\pi=\gamma\left[C_{m}+C_{c}\left(\frac{\bar{T}-\Omega}{\Omega}\right)\right],
\end{aligned}
$$

where $\gamma=-\left(F_{L_{R}}^{\prime}\right)^{2} / F F_{L_{R}}^{\prime \prime}$ that is the ratio of the labour elasticity of output to the elasticity of marginal product of $L_{R}$ (Fig. 4).

\section{References}

Becker, G. (1964). Human capital. New York: Columbia University Press.

Clerico, G. (1984). Economia della salute. Milan: Franco Angeli.

Chin, J., \& Grossman, G. M. (1990). Intellectual property rights and North-South trade. In R. W. Jones \& A. O. Krueger (Eds.), The political economy of international trade (pp. 90-107). Cambridge: Basil Blackwell Publishers.

Cropper, M. L. (1977). Health, investment in health, and occupation choice. The Journal of Political Economy, 85(6), 1273-1294.

Deardorff, A. V. (1992). Welfare effects of global patent protection. Economica, 59, 35-51.

Diwan, I., \& Rodrik, D. (1991). Patents, appropriate technology and North-South trade. Journal of International Economics, 30, 27-47.

Fink, C. (2000). How stronger patent protection in India might affect the behavior or transnational pharmaceutical industries. World Bank policy research working paper no. 2352, Washington.

Fuchs, V. R. (1966). The contribution of health services to the american economy. The Milbank Memorial Fund Quarterly, 44(4), 65-103.

Gersovitz, M., \& Hammer, J. S. (2004). The economical control of infectious diseases. The Economic Journal, 114(492), 1-27.

Ginarte, J. C., \& Park, W. G. (1997). Determinants of patent rights: A cross-national study. Research Policy, 26(3), 283-301.

Grossman, G. M., \& Helpman, E. (1991). Innovation and growth in the global economy. Cambridge: The MIT Press.

Grossman, G. M., \& Lai, E. (2004). International protection of intellectual property. American Economic Review, 94(5), 1635-1653.

Grossman, M. (1972). On the concept of health capital and the demand for health. The Journal of Political Economy, 80(2), 223-255.

Grossman, M. (2000). The human capital model. In A. J. Culyer \& J. P. Newhouse (Eds.), Handbook of health economics (pp. 347-408). Amsterdam: Elsevier Science B.V.

Kaul, I., Grunberg, I., \& Stern, M. (1999). Global public goods. New York: Oxford University Press.

Helpman, E. (1993). Innovation, imitation, and intellectual property rights. Econometrica, 61(6), $1247-80$.

Howitt, P. (2004). Health, human capital and economic growth: A schumpeterian perspective. In Guillem Lopez-Casasnovas, Luis Currais, \& Berta Rivera (Eds.), Economic growth and health. Cambridge: MIT Press.

Mansfield, E. (1985). How rapidly does new industrial technology leak out? The Journal of Industrial Economics, 34(2), 217-223. 
Maskus, K. E. (2000). Intellectual property rights in the global economy. Washington: Institute for International Economics.

Maskus, K. E., \& Penubarti, M. (1995). How trade-related are intellectual property rights? Journal of International Economics, 39(3-4), 227-248.

Murray, C. J. L., \& Lopez, A. D. (1996). Global health statistics. Global burden of disease and injury. Boston: Harvard School of Public Health.

Mushkin, S. J. (1962). Health as an investment. Journal Political Economy, 70(2), 129-57.

Nordhaus, W. D. (1969). Invention, growth and welfare: A theoretical treatment of technological change. Cambridge: The MIT Press.

Schwamm, L. H. (2018). The communicable nature of non-communicable diseases. The Lancet Neurology, 17(8), 665 .

Publisher's Note Springer Nature remains neutral with regard to jurisdictional claims in published maps and institutional affiliations. 